\title{
Impact of mathematical theory of exchange on national economic growth
}

\author{
Elena Novokshonova ${ }^{1,{ }^{*}}$, Marina Pivovarova ${ }^{2}$, and Vladimir Tyurnin ${ }^{2}$ \\ ${ }^{1}$ Pitirim Sorokin Syktyvkar State University, Oktyabrsky prospect, 55, Syktyvkar, 167001, Russia. \\ ${ }^{2}$ Department of Economic Theory, Financial University under the Government of the Russian \\ Federation, Leningradsky Prospekt 49, Moscow 125993, Russia.
}

\begin{abstract}
The paper presents the economic and mathematical theories of exchange by W.S. Jevons, L. Walras, J.E. Stiglitz, B. Holmström, and others. Theories of exchange are classified into classical (J.B. Say), neoclassical (A. Marshall), contractual (B. Holmström), natural scientific (V. Pareto), statistical. Mathematical models of exchange allow deepening the concept of competition. They show competition from the interaction of producers and the resulting uncertainty of exchange. It is shown that the emphasis on exchange to the detriment of production or, conversely, underestimation of exchange in economic regulation leads to a slowdown in economic growth. Research methods: abstraction, analysis and synthesis, the method of comparative descriptive analysis, economic and mathematical analysis.
\end{abstract}

\section{Introduction}

Great contribution to the study of exchange was made by K. Polanyi (historical direction), J. Homans (psychological direction); G. Becker and V.V. Radaev (sociological direction); K. Marx; A. Marshall (market direction); J.M. Keynes, J.E. Stiglitz. Studies of exchange will be incomplete if mathematical methods are not applied to them. And the purpose of the paper is to characterize the mathematical theory of exchange and its impact on national welfare through economic growth. Research on exchange took place from the very beginning of the development of economic science (canonical theory, mercantilism) and up until the 20th century, exchange was reduced to market exchange. Therefore, consideration of mathematical theories of exchange should begin with the theories of market exchange. In the canonical and classical theory of exchange, the formula of market exchange is: $\mathrm{D}=\mathrm{S}$, where $\mathrm{D}$ - the volume of goods supplied by the buyer for exchange; $\mathrm{S}$ the volume of goods supplied by the seller for exchange.

\section{Experimental part}

There are unobservable factors in a market exchange: the welfare of both the seller and the buyer. If the welfare of the seller and the buyer increase as a result of the exchange, the

\footnotetext{
* Corresponding author: einai@mail.ru
} 
exchange will take place, otherwise, the seller and the buyer will ignore each other. This model belongs simultaneously to the canonical and classical theories of exchange: the welfare gain from the exchange is ignored. The most famous equation of exchange in classical economic theory is the so-called Say's Identity. In the economy with a developed division of labor, the normal means for each person to purchase goods and services is the ability to produce equivalent goods and services for exchange.

Production not only increases the supply of goods but also creates demand for these goods due to the necessary coverage of production costs. Hence the conclusion (Say's Identity): "products are paid for products". In the economy where only countable money is used, where means of circulation are goods that are no different from other goods, the total value of the supply of all goods is always exactly equal to the aggregate demand for them.

Say's Identity can be written in the form: $\Sigma p i n i=1 D i \equiv \Sigma p j n j=1 S j$. The total demand for $\mathrm{n}-1$ goods is equal to the total supply of goods [2]. W.S. Jevons' equation of exchange is based on the law of diminishing marginal utility for the consumer. According to W.S. Jevons, the ratio in which two goods are exchanged must be inversely proportional to the last stages of utility of the exchanged goods. In terms of the modern theory of consumption, W.S. Jevons' equation of exchange is transformed into the familiar condition of consumer equilibrium: the equality of the marginal utilities of the purchased goods per unit price. Let's consider the mathematical expression of exchange according to Jevons.

Let " $a$ " and " $b$ " represent the quantities of two benefits that are exchanged between two individuals. Let $x$ and $y$ be the actual quantities of exchangeable goods "a" and " $b$ ". Let $\varphi$ and $\psi$ be the last stages of utility of the exchanged goods. Then $\varphi 1(\mathrm{a}-\mathrm{x}) \psi 1=\mathrm{y} \mathrm{x}=\varphi 2(\mathrm{x})$ $\psi 2(\mathrm{~b}-\mathrm{y})$. The ratio of the marginal utility of goods remaining after the exchange to the marginal utility of goods purchased in the exchange is inversely proportional to the proportion in which goods are exchanged. In modern terminology,

Jevons' equation of exchange can be written as: $M U x M U y=y x$ or $\mathrm{MUxPx}=\mathrm{MUyPy}=\mathrm{yx}$. Let's consider the exchange model of L. Walras, whose initial premises are the canonical and classical theories of exchange. Let there be one buyer and one seller. They exchange surplus. The seller presents the goods S for exchange, the buyer - the goods D. We write the exchange of surplus as follows: $\mathrm{S}=\mathrm{D}$.

Let's formulate a number of definitions: 1 . The proportion of exchange of goods $\mathrm{S}$ for goods D is called the price of goods $\mathrm{S} ; 2$. The proportion of exchange of goods D for goods $\mathrm{S}$ is called the price of goods $\mathrm{D} ; 3$. The lead party of the exchange is the buyer. The seller sells his goods not because there is a surplus, but because the seller will purchase goods D from the buyer; 4 . There is a double sale and a double purchase; 5 . The countable goods are involved in the exchange process. It can be written as an equation: $\mathrm{P}+\mathrm{S} \cdot \mathrm{pi}-\mathrm{Dpk}=0$, where $\mathrm{P}$ - the volume of the countable goods, $\mathrm{P} \in \mathrm{OP}$; pi - the price of goods $\mathrm{S}$; pk - the price of goods D. Countable goods removes territorial and temporal gaps in which the exchange without the intermediary goods (countable goods) is impossible [3].

The Walrasian model of exchange can also be written in this way. Let Xij* be the quantity of goods $\mathrm{j}$ offered for exchange, which gives the maximum wealth for the $\mathrm{i}$-th participant. $X i j$ - the actual quantity of goods $\mathrm{j}$ offered for exchange by the $\mathrm{i}$-th participant. $U i$ - the welfare of the $\mathrm{i}$-th participant, $U i \rightarrow \max . \mathrm{i}=2,3 \ldots . . \mathrm{n}$. If different exchange options are scanned, the actual quantity of goods offered for exchange will approach the optimal, and the welfare of participants of the exchange will be maximized: $p i j X i j \rightarrow p i j X i j *$ or in the general case: $\Sigma p i j X i j \rightarrow \Sigma p i j X i j *$. Then the following equality holds true: $X 11-X 11 *=\Sigma p(i-1)(j-1) X(i-1)(j-1) *-\mathrm{p}(i-1)(j-1) X(i-1)(j-1)$.

Let's formulate a number of additional definitions based on the Walrasian model of exchange: 
1. There are budgetary restrictions for the seller and the buyer $\mathrm{S} \in \mathrm{OS}$ (11) D€OD, where OS - the set of acceptable quantities of goods S; OD - the set of permissible quantities of goods $\mathrm{D}$;

2. In the absence of budgetary restrictions, in other words, when there is a moral, ethical and technological disorder, the maximum welfare is unlikely;

3. If exchanges will continue indefinitely and infinitely many times, the seller and the buyer will change the proportions and quantity of goods, maximizing the welfare from the exchange and will come to an optimal exchange: $S i *=D i *$. Under the condition i $\rightarrow \infty$; US $\rightarrow \max ; \mathrm{UD} \rightarrow \max ; S i *=D i *$ - the proportion of the exchange that gives the maximum welfare gain for the seller and the buyer; US, UD - welfare levels from the exchange for the seller and the buyer at various combinations of prices and quantities of goods.

The Walrasian model makes it possible to approach the notion of competition by specifying it. The share of the main players in the market is too vague and uncertain criterion of competition in the market. Suppose that under current restrictions, there are optimal prices, the optimal quantities at which the welfare from the exchange for the seller and the buyer will be maximum. Denote by DUi - the welfare gain of agent $i$ as a result of the exchange. At the initial and final points of the scanning of exchange proportions, $\mathrm{DUi}=0$, or $\mathrm{U} 1$ (mi, ai) $=0$, where $\mathrm{mi}$ and ai - the numbers of exchange transactions at the initial and final points, respectively, at which the welfare gain of agent 1 is zero. If one makes some combinations of prices and quantities of exchanged goods impossible, then the favorable combinations of prices and quantities of exchanged goods for participants of the exchange are probably excluded. The more exchange proportions that are excluded from scanning, the lower the level of competition, and vice versa, if all possible combinations of prices and quantities of goods in exchange are admissible, then exchange operations will be completely competitive. At a given price, competition is limited. In the classical and neoclassical theory of exchange, a sale with a negative price is not considered. The Walrasian model, on the contrary, makes it possible to understand the internal springs of such a paradoxical exchange - the retention of property incurs greater losses than the sale for a song. Selling goods for a song is an evidence of competitive exchange. Investment in the production of goods does not restrict competition; subsidizing consumption does not restrict competition.

The Walrasian model of exchange does not apply to the sector of public goods exchange. Let us consider the exchange of public goods with indivisible benefits, i.e. the second derivative of the production function of public goods is not zero.

J.E. Stiglitz offers three approaches for the theoretical representation of exchange in the public sector: the use of the replacement of private goods by public ones, the tax price, the demand and supply of public goods, and also the theory of utilitarianism and Rawlsianism. Society is always in a state of choice between private and public goods. The equilibrium point is determined by the sum of marginal substitutions of private goods for the sum of marginal substitutions of individuals for public goods, the sum of marginal rates of transformation of private goods for public goods, and the equality of marginal rates of substitution of private goods for public goods and norms for the transformation of private goods into public goods [11].

The optimal choice of private and public goods can be written as a formula: MRPTpppp = MRSpppp. The marginal rate of the product transformation of private goods into public goods is equal to the marginal rate of technical replacement of the production of private goods by public goods in production [11]. J.E. Stiglitz introduces into the analysis the concept of the tax price, the supply and demand of public goods. When determining the tax price, the supply and demand of public goods converge and find the intersection point the optimal value of the supply and demand of public goods. However, the achievement of equilibrium does not depend on individuals, but on the political process [11]. 


\section{Results}

Rawlsianism, like utilitarianism, suggests that individual preferences in the social economy are added vertically in contrast to the market economy, where individual preferences are added horizontally. In utilitarianism, the addition of individual preferences occurs additively, in Rawlsianism, it is differentiated. In either case, we can write: $\mathrm{W}=\Sigma$ Dini $=1$. The formula of the rawlsian-utilitarian concept of exchange in the social economy is: Max $\mathrm{W}=\Sigma U i n i=1+\Sigma U k n k=1$. The maximum welfare of a society is made up of the welfare of the poor (i) and the rich (k).

Utilitarianism shows that the maximum social welfare is achieved with equal distribution of social welfare among the rich and the poor. Rawlsianism shows that the maximum public welfare is achieved with the distribution that increases the welfare of the poor. In the limit, both in Rawlsianism and in utilitarianism, the following equality should be observed: $\Sigma U i n i=1=\Sigma U k n k=1$. The maximum welfare of all members of a society separately and jointly is achieved with an equalization distribution [11].

According to the theory of utilitarianism, in the exchange in the public sector, an increase in the utility of one individual should have equal weight with an increase in the utility of another individual. According to the theory of Rawlsianism, in the exchange in the public sector, an increase in the utility of one individual may also have unequal weight with an increase in the utility of another individual. Let's consider a society which has two groups - group 1 and group 2. General welfare consists of the welfare of individuals in groups 1 and 2 . Group 1 has a certain level of utility $U 1 *$, and group 2 has a level of utility $U 2 *$, where $U 2 *$ is at least no less than $U 1 *$. If we increase the utility of the second group, while keeping the utility of the first group unchanged, we will remain on the same public indifference curve: i.e. society will not improve its position. It does not want to sacrifice any utility of group 1 for the sake of some increase in the utility of group 2 . If both groups initially have the same levels of utility, the welfare of society increases only when the welfare of both group 1 and group 2 increases, and this increase is equal to the smallest increase in the welfare of any group.

According to Stiglitz, exchange in the public sector is reduced to the choice of proportions of exchange between a decrease in the welfare of one group/one individual and an increase in the welfare of another group/another individual [11]. Exchange in the public sector according to the model of utilitarianism or Rawlsianism differs from market exchange only in the way of formation of supply and demand, but not in substance. In a market exchange, supply and demand are not divided into its component parts. In utilitarianism/Rawlsianism, supply and demand are divided into individual welfare, the meeting of supply and demand occurs as a redistribution of social welfare between groups of the population. In one case, equilibrium is reached at the point of equal distribution of public welfare, at the other - at the point of equality of supply and demand for public goods.

The "Principal-Agent" theory is applicable to the sector of public goods exchange. The "Principal-Agent" theory puts the parties of the exchange initially in an unequal position. One party of the exchange gives an assignment (principal), the other - carries out this assignment and receives a reward (agent). The exchange involves trusting relationships, general information systems, the creation of targeted motives, and the establishment of systems for monitoring the fulfillment of obligations of the parties of the exchange.

First proposed by M. Jensen and V. Meckling in 1932 [9, 17], the "Principal-Agent" theory was further developed in the second half of the 20th century and is being actively developed at the present time. The "Principal-Agent" theory is meaningful in terms of its application to the public sector and ownership structure in a company $[15 ; 18]$. B. Holmtström proposed the following mathematical model of exchange in collective 
production. Suppose there are $\mathrm{n}$ agents. Each agent has a number i. Each agent performs unobservable actions ai.

Denote the collective action by $\mathrm{Ai},(\mathrm{ai} \in \mathrm{Ai}=[0, \infty]$. Each agent incurs non-cash costs vi. We denote conventional conditions by IR. Ai $\rightarrow$ IR, vi $\rightarrow$ IR. Suppose vi $(0)=0$, $\mathrm{a}=(\mathrm{a} 1 \ldots$....an $) \in \mathrm{A} \equiv \Sigma \mathrm{A} i n i=1$. Let si $(\mathrm{x})$ be the share of the $\mathrm{i}$-th agent in the income of collective production. The income is distributed among the agents. The function $\Sigma$ Aini $=1$ is separable in money and in kind, linear in money. Let the agent strive for a positive difference between his cash receipts and costs (u), i.e. ui (mi, ai) $=m i-v i(a i)$, where mi - a certain coefficient of linear function. vi (ai) - the non-cash cost of agent $i$. The agent's net cash receipts at the start and end points of production are equal to zero. The rule according to which the shares are distributed among agents is as follows: if $\operatorname{si}(\mathrm{x}) \geq 0, \mathrm{i} \ldots \ldots \mathrm{n}$, then $\Sigma \operatorname{sini}=1(\mathrm{x})=\mathrm{X}$ for all $\mathrm{x}$, where $\mathrm{X}-$ the collective income distributed among agents, si - the volume of agent i's remuneration, $x$ - the amount of agent i's remuneration. The collective income distributed among the agents is equal to the sum of the cash receipts of all the agents. Under these conditions, the Pareto optimum is written as: $a^{*=} \arg [x(a)-$ $\Sigma v i n i=1(a \mathrm{i})$. The optimal point of exchange in the "Principal-Agent" relationship system is equal to the extremum of the function of the difference between the monetary reward of all agents and their costs. If the fraction of shared distribution of the collective income is differentiable, then we can find the point of Nash equilibrium. This is "a", with which the equality $s i^{\prime} x i^{\prime}-v i^{\prime}=0 \mathrm{i}=1$ holds, where: $s i^{\prime} x i^{\prime}-v i^{\prime}$ - the first derivative of the function of the agent's net income with respect to "a".

B. Holmström emphasizes that the first derivative of the original equation is $1 . \Sigma s i$ ' $n i=1=1$, and the derivative of the shared distribution of collective income is 0 . The equilibrium condition requires a zero increase in remuneration. Thus, with equal net remuneration of agents to the total amount of distributed income, the Nash optimality condition will not be satisfied. Hence the conclusion: in a collective economy, efforts are needed to optimize exchange or to manage collective production, a mechanism is needed for the distribution of fines and rewards. The exchange involves some cultural content, i.e. a set of historically formed norms and proportions of wealth, the violation of which leads to the dehumanization of production and consumption. But situations of moral hazard are considered, when the norms recorded under the contract are not respected. B. Holmström studied the moral hazard (opportunistic behavior) of the parties of the agency contract. O.T. Lebedev and A.R. Kankovskaya suggested using the mathematical apparatus of vector analysis to describe collective work and the exchange in it [5]. The mathematical representation of the exchange in the "Principal-Agent" relationship system is given in the work of L.S. Tarasevich, P.I. Grebennikov, A.I. Leussky [13, p. 246-249].

\section{Conclusion}

Important place among the models of exchange is occupied by models that have a natural scientific character. These are models of linear programming, Pareto efficiency, game theory, entropy of the golden ratio, the law of large numbers. The statistical model of exchange is a model for calculating the gross national product. Natural scientific and statistical models of exchange are not considered in this paper because they are described in detail in the scientific, educational and reference literature. A review of economic and mathematical models of exchange shows that exchange is important in the production and consumption. However, the role of exchange in social reproduction should not be both exaggerated and underestimated. All stages of social reproduction (production, distribution, exchange, and consumption) are equally active for economic growth. Exaggeration of the role of exchange is obvious in a situation where there is a market for buyers, an 
understatement - when there is a market for sellers. Both have a negative effect on economic growth.

\section{References}

1. A. Berle, G. Means, The Modern Corporation and Private Property (Harcourt, Brace and World, N.Y., 1968)

2. B. Holmctröm, The Bell Journal of Economics 13-2, 324-340 (1982)

3. M. Jensen, W. Meckling Theory of the Firm Managerial Behavior, Agency Costs and Ownership Structure, Journal of Financial Economics (1976)

4. S. Ross, American Economic Review 63-2, 134-139 (1973)

5. A. Edgar, National BIM Standard, Version 1, Part 1 - Overview, Principles, \& Methodologies (2007)

6. B. Hardin, BIM and Construction Management: Proven Tools, Methods, and Workflows (2009)

7. C.M. Eastman, BIM Handbook: A Guide to Building Information Modeling for Owners, Managers, Designers, Engineers and Contractors (2008)

8. H.-Y. Chong, X. Wang, C.-Y. Lee, A mixed review of the adoption of Building Information Modelling (BIM) for sustainability, Journal of Cleaner Production (2016)

9. J.M. Cooksey, The integration of building information modeling (BIM) into civil engineering curricula (2011) 